\title{
Analysis and Design of a Transformerless Boost Inverter for Stand-Alone Photovoltaic Generation Systems
}

\author{
Zhixiang Yu, Xuefeng Hu, Zhilei Yao, Lezhu Chen, Meng Zhang, and Shunde Jiang
}

\begin{abstract}
A novel transformerless boost inverter for standalone photovoltaic generation systems is proposed in this paper. The proposed inverter combines the boost converter with the traditional bridge inverter. The switch $S_{1}$ not only realizes the boost function but also participates in inverting process. The inverter has a higher voltage gain and good characteristics when the inductor $L_{1}$ is operated in discontinuous mode (DCM) and the nonpolarized capacitor can be chosen as bus capacitor, which makes the volume smaller and the service life of the inverter is increased. The inverter consists of five switches in which only two switches are operated at high frequency state and a monopole sinusoidal pulse width modulation (SPWM) strategy is used. Therefore, the modulation strategy of switches is very simple and the switching loss is reduced. The principle of inverter is described in detail and mathematical models are built by small-signal analysis. Finally, the correctness of the theoretical analysis is verified by simulation and experiment.
\end{abstract}

Index Terms-Boost inverter, discontinuous mode (DCM), monopole sinusoidal pulse width modulation (SPWM), nonpolarized capacitor, photovoltaic generation systems, transformerless.

\section{INTRODUCTION}

$\mathrm{I}$ the last ten years, the photovoltaic (PV) power systems have become very popular among the renewable energy sources[1]-[28]. Normally, the inverter is the key interface between the solar cells and the AC load. However, the output voltage of the PV systems is generally low. Consequently, inverters need to have the ability to boost the output voltage of $\mathrm{PV}$ in order to maintain a stable AC voltage for the load [1]-[2].

The traditional voltage source inverter is a step-down inverter. When the input voltage is low, the traditional voltage source inverter is usually added a DC-DC boost circuit at its front stage. So the step-up inverter can be realized by

\footnotetext{
Manuscript received July 15, 2019; revised September 4, 2019; accepted September 12, 2019. Date of publication December 30, 2019; date of current version November 19, 2019. This work was supported by the National Natural Science Foundation (51577002), Top-notch Personnel Foundation of the Anhui Higher Education Institutions of China (gxbjZD13). This paper was presented in part at the 2019 IEEE 10th International Symposium on Power Electronics for Distributed Generation Systems (PEDG), Xi'an, China, June 2019.

Z. Yu, X. Hu, L. Chen, M. Zhang, and S. Jiang are with Anhui Key Laboratory of Power Electronics and Motion Control Technology, the College of Electrical and Electronic Engineering, Anhui University of Technology, Ma'anshan, China (e-mail: hxu-123@163.com).

Z. Yao is with the Yancheng Institute of Technology, Yancheng, China (e-mail: 953276911@qq.com).

Digital Object Identifier 10.24295/CPSSTPEA.2019.00029
}

cascading the DC-DC converter and the traditional full bridge inverter [3]. However, due to the large number of switching devices, complex control strategy and higher cost in this two stages inverter. The flyback micro-inverter can step up the input voltage, and isolate the output and the input. However, the volume and cost of the inverter are relatively high due to the existence of transformers. Some single stage boost inverters are studied in [1]-[20], for example: $Z$ source inverter [4]-[5], double Boost inverter [8]-[9], double Cuk integrated inverter [10]-[11], Buck-Boost integrated inverter [12]$[13]$ and so on. The typical $\mathrm{Z}$ source inverter can achieve the function of the boost by using the controlled direct connection of the upper and lower bridge arm power switches. However, it has many disadvantages, such as complex topology, starting shock and oscillation, voltage gain restricted by duty cycle and modulation ratio. The inverter is a combination of two improved Cuk DC converters by input series and output parallel in [10]. By setting the appropriate regulator, the inverter can obtain good dynamic and static performance. However, the inverter requires two independent input power supplies and two independent boost inductors, which leads to low utilization rate of power source and the large volume of the circuit. Moreover, the voltage gain of the inverter circuit is low. The inverter proposed in [11] is composed of an inverting and a non inverting Cuk converter. Due to the inherent up-down voltage capacity of the Cuk converter, the output voltage can be higher or lower than the input voltage. But the inverter has six switches and four switches are operated at high frequency, so it is a challenge to improve the efficiency of the inverter.

A new boost transformerless photovoltaic inverter is proposed in this paper, which integrates boost converter with the traditional full bridge inverter. The inverter has characteristics of high gain, high integration, few power devices and easy to control. Moreover, the proposed inverter adopts monopole sinusoidal pulse width modulation (SPWM) strategy to realize the voltage pumping and the control of output voltage.

\section{A Novel Transformerless Step-Up InVERTER}

\section{A. The Topology of Proposed Inverter}

This paper presents a boost transformerless inverter topology, 


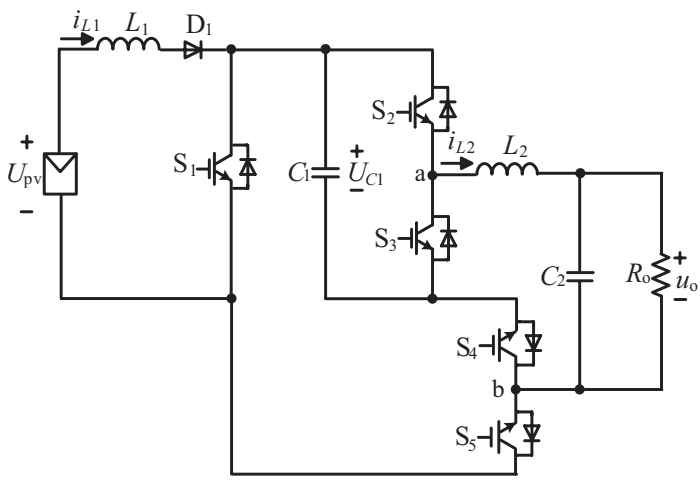

Fig. 1. The configuration of proposed inverter.

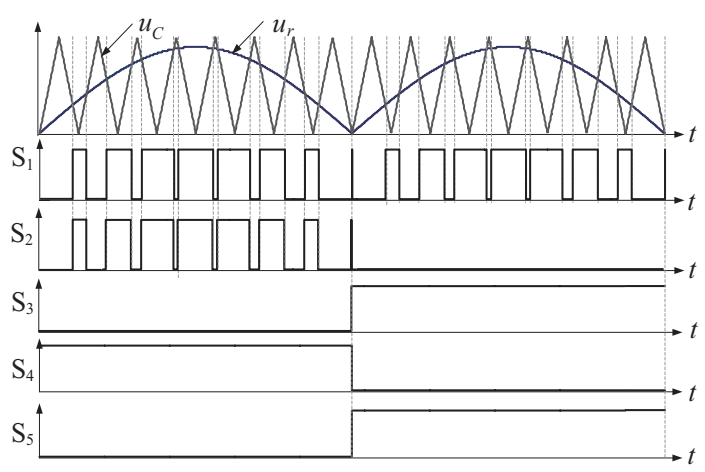

Fig. 2. The modulation of power switches.

as shown in Fig. 1. The topology consists of five power switches $\mathrm{S}_{1} \sim \mathrm{S}_{5}$, two energy storage components, inductance $L_{1}$ and capacitance $C_{1}$, load resistor $R_{0}$, filter inductance $L_{2}$, filter capacitor $C_{2}$, diode $\mathrm{D}_{1}$. The body diode of the power switches $\mathrm{S}_{1} \sim \mathrm{S}_{5}$ is respectively called $\mathrm{D}_{\mathrm{S1}} \sim \mathrm{D}_{\mathrm{S} 5}$. It can be seen that the proposed inverter is integrated with boost converter and the traditional full bridge inverter by sharing the power device $S_{1}$. The DC power source is supplied to the inductor $L_{1}$ through $\mathrm{S}_{1}$ and the voltage ripple of capacitor $C_{1}$ is smaller in the steady state. The diode $\mathrm{D}_{1}$ compel the energy to flow from the DC power source to the load. In order to simplify circuit analysis, the assumptions are as follows:

(1) The filter inductor $L_{2}$ is large enough and its current is essentially constant in one switching period. (2) All power switches, diodes, inductors and capacitors are ideal components, that is, the effect of parasitic parameters is not considered. (3) The capacitors $C_{1}$ and $C_{2}$ are large enough to keep $U_{C 1}$ and $U_{C 2}$ constant during a switching period.

\section{B. Analysis of Operational Principle}

The power switches of the inverter are based on monopole SPWM and the modulation strategy is shown in Fig. 2. The SPWM signal used by the switch $\mathrm{S}_{1}$ is generated by the comparison of the absolute value of the sine wave as modulation wave with the triangle wave as the carrier wave. The control signal of the switch $S_{2}$ is the same as that of the $S_{1}$
TABLE I

Switching Sequence of Proposed Inverter

\begin{tabular}{cccccc}
\hline \hline & $\mathrm{S}_{1} / \mathrm{D}_{\mathrm{S} 1}$ & $\mathrm{~S}_{2} / \mathrm{D}_{\mathrm{S} 2}$ & $\mathrm{~S}_{3} / \mathrm{D}_{\mathrm{S} 3}$ & $\mathrm{~S}_{4} / \mathrm{D}_{\mathrm{S} 4}$ & $\mathrm{~S}_{5} / \mathrm{D}_{\mathrm{S} 5}$ \\
\hline Mode I & $1 / 0$ & $1 / 0$ & $0 / 0$ & $1 / 0$ & $0 / 0$ \\
Mode II & $0 / 0$ & $0 / 0$ & $0 / 1$ & $1 / 1$ & $0 / 1$ \\
Mode III & $0 / 0$ & $0 / 0$ & $0 / 1$ & $1 / 0$ & $0 / 0$ \\
Mode IV & $1 / 0$ & $0 / 0$ & $1 / 0$ & $0 / 0$ & $1 / 0$ \\
Mode V & $0 / 0$ & $0 / 0$ & $1 / 0$ & $0 / 1$ & $1 / 1$ \\
Mode VI & $0 / 0$ & $0 / 0$ & $1 / 0$ & $0 / 1$ & $1 / 0$ \\
\hline \hline
\end{tabular}

when it works in the positive half cycle of sine wave. While it is turned off in the negative half cycle of the sine wave.

The proposed inverter operates in discontinuous current mode of boost inductor. Table I shows the switching sequence of the proposed inverter in one switching cycle. There are six operating modes in one switching cycle. The six operating modes of the circuit are shown in Fig. 3. The mode I, II and III operate in the positive half period of the output voltage. While the mode IV, V and VI operate in the negative half cycle. The respective analysis is as follows and the key waveforms of the proposed inverter in discontinuous mode (DCM) are shown in Fig. 4.

The power switches $S_{1}$ and $S_{2}$ operate at high frequency in the positive half cycle. So they are in the alternating state of turn-on and turn-off. The power switches $\mathrm{S}_{3}$ and $\mathrm{S}_{5}$ are in turnoff state and the power switch $\mathrm{S}_{4}$ is conducted. The circuit has six modes of operation.

Mode I $\left[t_{0} \sim t_{1}\right]$ The equivalent circuit is shown in Fig. 3(a). At $t=t_{0}$, the switches $\mathrm{S}_{1}, \mathrm{~S}_{2}, \mathrm{~S}_{4}$ and diode $\mathrm{D}_{1}$ are turned on. While switch $\mathrm{S}_{3}$ and $\mathrm{S}_{5}$ are turned off. At this moment, the input DC power $U_{\text {in }}$ charges the inductor $L_{1}$ through the diode $\mathrm{D}_{1}$ and the power switch $\mathrm{S}_{1}$. The inductance current $i_{L 1}$ increases linearly. The capacitor $C_{1}$ charges the inductor $L_{2}$ and supplies power to the $R_{\mathrm{O}}$ through switches $\mathrm{S}_{2}$ and $\mathrm{S}_{4}$.

$$
i_{L 1}(t)=\frac{U_{\text {in }}}{L_{1}}\left(t-t_{0}\right)+i_{L 1}\left(t_{0}\right)
$$

Mode II $\left[t_{1} \sim t_{2}\right]$ The equivalent circuit is shown in Fig. 3(b). At $t=t_{1}$, the switch $\mathrm{S}_{4}$ and diode $\mathrm{D}_{\mathrm{S} 3}$ are turned on. Switches $\mathrm{S}_{1}, \mathrm{~S}_{2}, \mathrm{~S}_{3}$ and $\mathrm{S}_{5}$ are turned off. At this moment, the $U_{\text {in }}$ and $L_{1}$ charge $C_{1}$ through the $\mathrm{D}_{1}$ and $\mathrm{D}_{\mathrm{S} 4}$. The $i_{L 2}$ can not change suddenly at the load terminal. So $L_{2}$ continues to charge $R_{\mathrm{O}}$ through $\mathrm{D}_{\mathrm{S} 3}$. At the moment of $t_{2}, i_{L 1}$ is linearly reduced zero.

$$
i_{L 1}(t)=\frac{U_{\text {in }}-U_{C 1}}{L_{1}}\left(t-t_{1}\right)+i_{L 1}\left(t_{1}\right)
$$

Mode III $\left[t_{2} \sim t_{3}\right]$ The equivalent circuit is shown in Fig.3(c). At $t=t_{2}$, the switch $\mathrm{S}_{4}$ is still turned on. Switches $\mathrm{S}_{1}, \mathrm{~S}_{2}, \mathrm{~S}_{3}$ and $\mathrm{S}_{5}$ are turned off. At this moment, there is no charging loop because the inductance current $i_{L 1}$ is zero. The inductor $L_{2}$ continues to charge the load $R_{\mathrm{O}}$ through the body diode $\mathrm{D}_{\mathrm{S} 3}$ until $t_{3}$ and the mode III ends.

$$
i_{L 1}(t)=0
$$




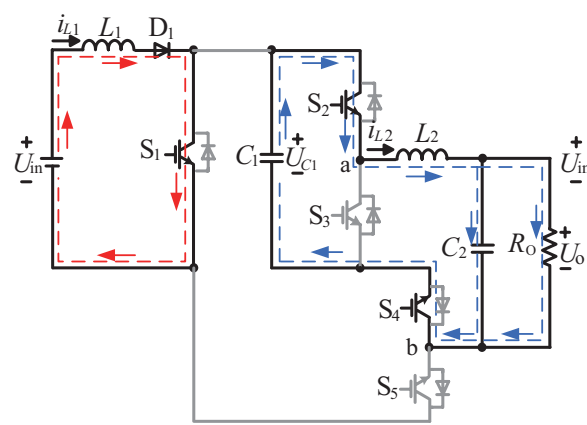

(a)

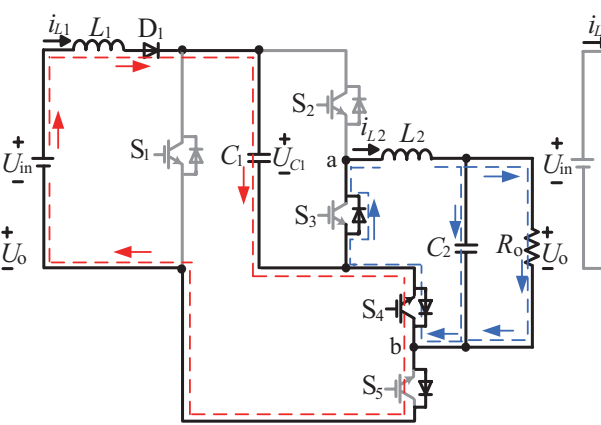

(b)

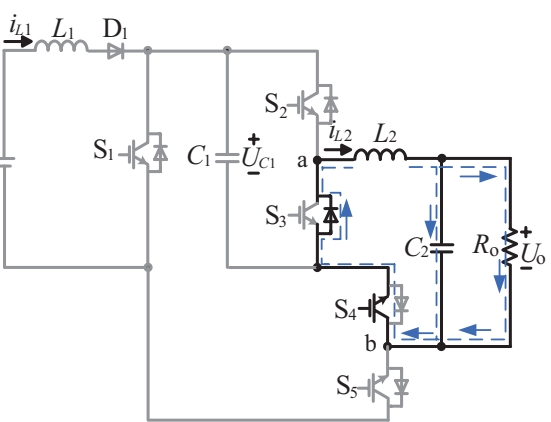

(c)

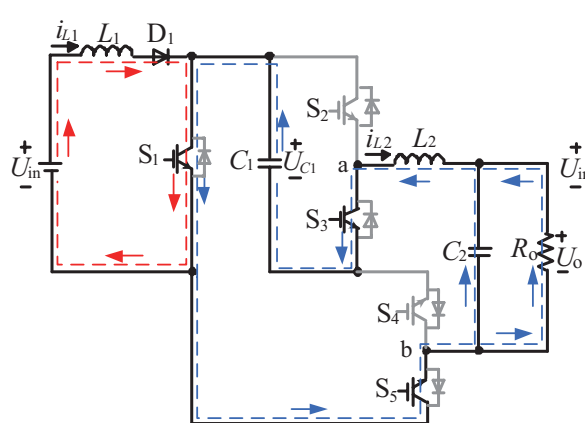

(d)

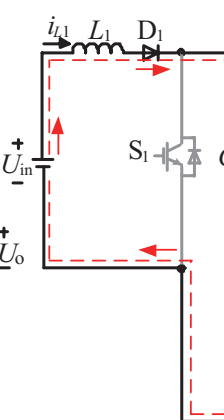

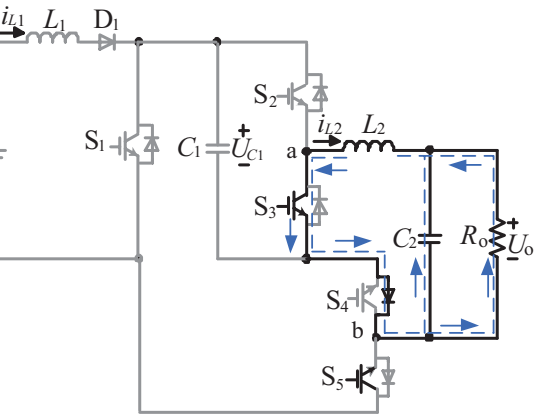

(f)

Fig. 3. Equivalent modal diagram of circuit. (a) Mode I. (b) Mode II. (c) Mode III. (d) Mode IV. (e) Mode V. (f) Mode VI.

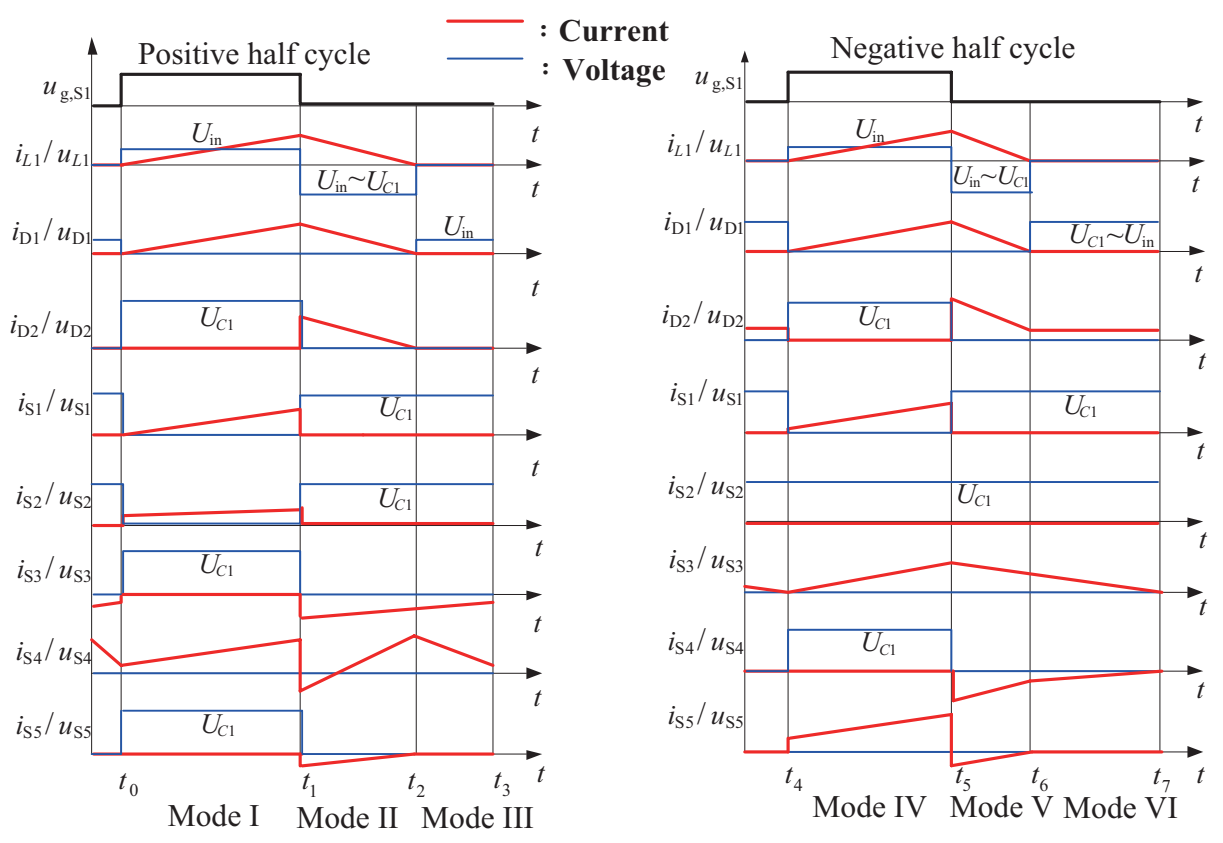

Fig. 4. The key waveforms of the proposed converter in DCM operation.

Mode IV $\left[t_{4} \sim t_{5}\right]$ The equivalent circuit is shown in Fig. 3(d). At $t=t_{4}$, switches $\mathrm{S}_{1}, \mathrm{~S}_{3}$ and $\mathrm{S}_{5}$ are turned on. While $\mathrm{S}_{2}$ and $\mathrm{S}_{4}$ are turned off. At this moment, $U_{\text {in }}$ charges $L_{1}$ through the diode $\mathrm{D}_{1}$ and the switch $\mathrm{S}_{1}$. The $i_{L 1}$ increases linearly. The capacitor $C_{1}$ charges the inductor $L_{2}$ and supplies power to the $R_{\mathrm{O}}$ through switches $\mathrm{S}_{1}, \mathrm{~S}_{3}$ and $\mathrm{S}_{5}$. At $t=t_{5}$, the mode IV ends.

$$
i_{L 1}(t)=\frac{U_{\text {in }}}{L_{1}}\left(t-t_{4}\right)+i_{L 1}\left(t_{4}\right)
$$

Mode V $\left[t_{5} \sim t_{6}\right]$ The equivalent circuit is shown in Fig. 3(e). At $t=t_{5}$, switches $\mathrm{S}_{3}$ and $\mathrm{S}_{5}$ are turned on while switches $\mathrm{S}_{1}$, $\mathrm{S}_{2}$ and $\mathrm{S}_{4}$ are turned off. At this moment, the input power $U_{\text {in }}$ and $L_{1}$ charge $C_{1}$ through $\mathrm{D}_{1}$ and $\mathrm{D}_{\mathrm{S} 4}$. The $i_{L 2}$ can not change suddenly at the load terminal, so the inductance $L_{2}$ continues to charge $R_{\mathrm{O}}$ through $\mathrm{S}_{3}$ and $\mathrm{D}_{\mathrm{S} 4}$. At the moment of $t_{6}$, the $i_{L 1}$ is linearly reduced zero and the mode $\mathrm{V}$ ends.

$$
i_{L 1}(t)=\frac{U_{\text {in }}-U_{C 1}}{L_{1}}\left(t-t_{5}\right)+i_{L 1}\left(t_{5}\right)
$$




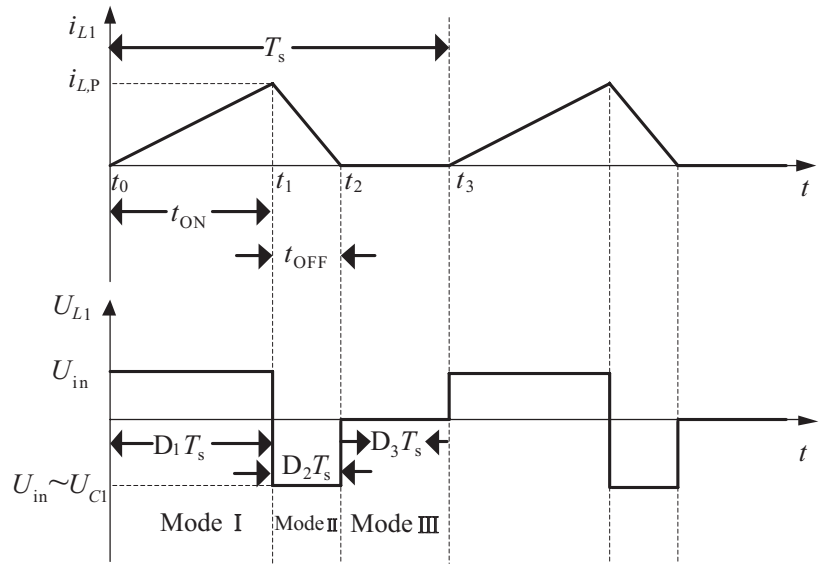

Fig. 5. The current and voltage waveform of inductance in DCM.

Mode VI $\left[t_{6} \sim t_{7}\right]$ The equivalent circuit is shown in Fig. 3(f). At $t=t_{6}$, switches $\mathrm{S}_{3}$ and $\mathrm{S}_{5}$ are still turned on. Switches $\mathrm{S}_{1}$, $\mathrm{S}_{2}$ and $\mathrm{S}_{4}$ are turned off. At this moment, there is no charging loop because the inductance current $i_{L 1}$ is zero. $L_{2}$ continues to charge $R_{\mathrm{O}}$ through $\mathrm{S}_{3}$ and $\mathrm{D}_{\mathrm{S} 4}$ until $t_{7}$ and the mode VI ends.

$$
i_{L 1}(t)=0
$$

\section{Voltage Gain and Parameters of the Proposed INVERTER}

\section{A. Analysis of Voltage Gain}

From the above analysis, one can see that the duty cycle $d_{i}$ of the signal $\mathrm{S}_{1}$ in each carrier period varies. Assuming that the duty ratio of $\mathrm{S}_{1}$ is $d_{i}$ in $i$ carrier cycle. The $m$ is the modulation ratio. According to the regular symmetry sampling rule in [21], the duty cycle can be expressed as (7).

$$
d_{i}=m \sin \omega t_{i}
$$

Since the inductance $L_{1}$ of the inverter operates in DCM, the $i_{L 1}$ reaches the maximum value $I_{L, \mathrm{P}}$ at the moment of $t_{1}$ and drops to zero when the time is $t_{2}$. The current $i_{L 1}$ remains zero between the time of $t_{2}$ and $t_{3}$. As you can see from Fig. 5, the formula can be obtained as follows: $d_{i}^{\prime}=\left(t_{2}-t_{1}\right) / T_{\mathrm{S}}, d_{i}+d_{i}^{\prime}<1$.

According to the voltage second balance of inductor $L_{1}$, the following equation can be expressed as:

$$
U_{\text {in }} d_{i} T_{\mathrm{S}}=\left(U_{C 1}-U_{\text {in }}\right) d_{i}^{\prime} T_{\mathrm{S}}
$$

If the loss of all components in this circuit is neglected, the input power is equal to the output power and thus the formula can be obtained as:

$$
U_{\text {in }} I_{\text {in }}=\left(U_{\text {om }} / \sqrt{2}\right)^{2} / R_{0} .
$$

where $U_{\text {om }}$ is amplitude of the output voltage of the inverter.

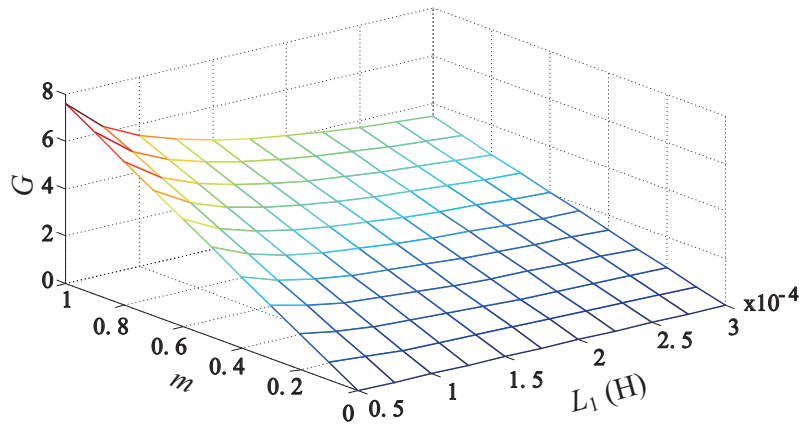

Fig. 6. Diagram of voltage gain $G$ and $L_{1}, m$.

It can be expressed as: $U_{\text {om }}=m U_{C 1}$. Since the input average current is equal to the inductance average current, the following equations can be written as:

$$
I_{\text {in }}=I_{L 1},
$$

and the average value of $i_{L 1}$ can be obtained as:

$$
I_{L 1}=\left(d_{i}+d_{i}^{\prime}\right) I_{L, \mathrm{P}} / 2
$$

According to (8) (11), the equations of the input voltage and the DC bus voltage can be derived as:

$$
\frac{U_{C 1}}{U_{\text {in }}}=\frac{1}{2}\left(1+\sqrt{1+\frac{4 d_{i}^{2} T_{\mathrm{S}} R_{0}}{L_{1} m^{2}}}\right) .
$$

The $d_{i}$ is taken as the valid value and the voltage gain can be expressed as:

$$
G=\frac{U_{\mathrm{om}}}{U_{\mathrm{in}}}=\frac{m}{2}\left(1+\sqrt{1+\frac{2 T_{\mathrm{S}} R_{\mathrm{O}}}{L_{1}}}\right) .
$$

Fig. 6 shows the three-dimensional relationships of voltage gain $G$ versus inductance $L_{1}$ and modulation ratio $m$ when $f_{\mathrm{S}}=$ $20 \mathrm{kHz}, R_{\mathrm{O}}=100 \Omega$ are given. As can be seen from Fig. 6 , the $G$ increases when the $m$ increases or the $L_{1}$ decreases.

\section{B. Range of Modulation Ratio $m$}

The range of modulation ratio $m$ is discussed based on the open-loop condition. According to (8), the $d_{i}^{\prime}$ can be obtained as:

$$
d_{i}^{\prime}=\frac{U_{\text {in }} d_{i}}{U_{C 1}-U_{\text {in }}} .
$$

Because $d_{i}+d_{i}^{\prime}<1$, the duty cycle $d_{i}$ can be expressed as:

$$
d_{i}<\frac{1}{\frac{U_{\text {in }}}{\left(U_{C 1}-U_{\text {in }}\right)}+1} \text {. }
$$


According to (7), $\sin \omega t_{i} \in\left(\begin{array}{ll}0 & 1\end{array}\right)$, the range of modulation ratio $m$ can be derived as:

$$
m<\frac{1}{\frac{U_{\text {in }}}{\left(U_{C 1}-U_{\text {in }}\right)}+1} .
$$

When the intermediate variable $U_{C 1}$ is represented by an independent variable $m$. According to (16), the range of modulation ratio $m$ can be derived as:

$$
m<\frac{U_{\text {om }}}{U_{\text {om }}+U_{\text {in }}} .
$$

\section{The Value of Boost Inductor}

In order to ensure the inverter is operated in DCM, the critical inductance of the boost inverter is derived firstly.

When the boost inductor works in DCM, the inductance current is exactly zero at the start and at the end of each switching cycle. The average current of inductance is equal to half of the variation of inductance current. It is assumed that the threshold inductance is $L_{\mathrm{C}}$. According to (10) and (11), the following equation can be expressed as:

$$
I_{\text {in }}=I_{L_{\mathrm{C}}}=I_{L, \mathrm{P}} / 2 .
$$

The formula between current and voltage is as follows:

$$
I_{L, \mathrm{P}}=U_{\text {in }} d_{i} T_{\mathrm{S}} / L_{\mathrm{C}} .
$$

According to (9), (18) and (19), the following equation can be derived as:

$$
U_{\text {in }} d_{i} T_{\mathrm{S}} /\left(2 L_{\mathrm{C}}\right)=m^{2} U_{C 1}^{2} /\left(2 R_{0} U_{\text {in }}\right) .
$$

The critical inductance $L_{\mathrm{C}}$ can be obtained as:

$$
L_{\mathrm{C}}=U_{\mathrm{in}}^{2} d_{i} T_{\mathrm{S}} R_{\mathrm{o}} / U_{\mathrm{om}}^{2} .
$$

As we can see from (21), $L_{\mathrm{C}}$ is related to input voltage, load and modulation ratio. In order to ensure the inductor current is always discontinuous throughout the entire range of $U_{\text {in }}$. The value of the inductor should be less than $L_{\mathrm{C}}$. The threedimensional image of the inductance $L_{\mathrm{C}}$ is shown in Fig. 7, in which $d_{i}=0.7, f=20 \mathrm{kHz}, U_{\mathrm{om}}=155 \mathrm{~V}$.

\section{Design of the Bus Capacitor}

During the operation of the boost inverter, the design of the capacitor mainly considers the voltage stress and the maximum acceptable voltage ripple across it. The capacitor is charged and discharged continuously with the change of the power switch state. The relation between the charge quantity and the capacitance value is satisfied as follow:

$$
\Delta Q=C \Delta U_{C 1}=I_{C} \Delta T .
$$

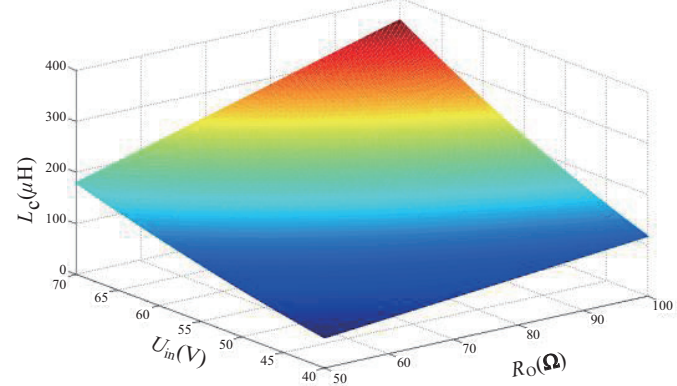

Fig. 7. Three-dimensional image of the threshold inductance $L_{\mathrm{C}}$.

In a switching cycle, $\Delta Q$ is the quantity of charge during charging or discharging process of capacitors. $\Delta U_{C 1}$ is the value of the capacitor voltage ripple. $I_{C}$ is the average current of capacitor during charging or discharging process. $\Delta T$ is the charging time or discharging time. Therefore, the value of the capacitor can be selected according to (23), in which $P_{\mathrm{O}}$ represents the output power.

$$
C_{1} \geqslant \frac{P_{0} d_{i}}{\left(U_{C 1}-U_{\text {in }}\right) \Delta U_{C 1} f_{\mathrm{S}}}
$$

In order to ensure the performance of the inverter, the value of capacitor voltage ripple is limited to $1 \%$ of $U_{C 1}$. Thus, the value of $C_{1}$ should be greater than $15 \mu \mathrm{F}$. The capacitor value of the inverter is selected for $47 \mu \mathrm{F}$.

\section{E. Design of Filter Inductor and Capacitor}

The design method of filter inductance and capacitor is $K$ low-pass filter in proposed inverter refer to the design in reference [22]. This design method can be expressed as: $K=$ $R^{2}=L / C, R=(0.5-0.8) R_{0}$.

The cut-off frequency $f_{\mathrm{C}}$ is increased by 10 times, which is the carrier frequency $f_{\mathrm{S}}$. And then:

$$
\begin{gathered}
L=\frac{R}{2 \pi f_{\mathrm{C}}} \\
C=\frac{1}{2 \pi f_{\mathrm{C}} R} .
\end{gathered}
$$

It is calculated that the value of $L_{2}$ is $3.7 \mathrm{mH}$ and the value of $C_{2}$ is $1.3 \mu \mathrm{F}$. Therefore, the value of filter inductance and filter capacitor is respectively $3 \mathrm{mH}$ and $10 \mu \mathrm{F}$ in proposed inverter.

\section{InVerter Modeling ANd Controller Design}

\section{A. Inverter Modeling}

This paper builds a state space averaged model to obtain a linearized model of the proposed inverter. In addition, designing a suitable controller to achieve good steady-state performance and dynamic characteristics by small-signal analysis. To simplify the analysis, following assumptions are made. Components including capacitors and inductors are ideal 
devices, regardless of the effects of parasitic parameters and the initial conditions of elements are zero. Inductor currents $\left(i_{L 1}\right.$, $\left.i_{L 2}\right)$ and capacitor voltages $\left(U_{C 1}, U_{C 2}\right)$ are considered as state variables $x$.

$$
x=\left[\begin{array}{llll}
i_{L 1} & i_{L 2} & U_{C 1} & U_{C 2}
\end{array}\right]^{T}
$$

The input voltage $\left(U_{\text {in }}\right)$ is selected as the input variable $u$, and the output voltage $\left(U_{\mathrm{O}}\right)$ is the output variable $y$, and the state space equation can be written:

$$
\left\{\begin{array}{l}
\dot{x}=A x+B u \\
y=C x
\end{array} .\right.
$$

The expressions for the state variables during three operating modes are given in Table II.

For easier analysis, the duty ratio weighting factor of the converter mode $\mathrm{I}$ is $\mathrm{D}_{1}\left(\mathrm{D}_{1}=d_{i}\right)$, the duty ratio weighting factor of the mode II is $\mathrm{D}_{2}\left(\mathrm{D}_{2}=d_{i}^{\prime}\right)$, and the duty ratio weighting factor of the mode III is $\mathrm{D}_{3}\left(\mathrm{D}_{3}=1-d_{i}-d_{i}^{\prime}\right)$. By using the average state space method, the coefficient matrixes $A, B$ and $C$ can be calculated by the following formulas:

$$
\begin{gathered}
A=\left[\begin{array}{cccc}
0 & 0 & 0 & 0 \\
0 & 0 & \frac{\mathrm{D}_{1}}{L_{2}} & -\frac{1}{L_{2}} \\
\frac{\mathrm{D}_{2}}{C_{1}} & -\frac{\mathrm{D}_{1}}{C_{1}} & 0 & 0 \\
0 & \frac{1}{C_{2}} & 0 & -\frac{1}{R C_{2}}
\end{array}\right] \\
B=\left[\begin{array}{cccc}
\mathrm{D}_{1}+\mathrm{D}_{2} & 0 & 0 & 0
\end{array}\right]^{T} \\
C=\left[\begin{array}{llll}
0 & 0 & 0 & 1
\end{array}\right] .
\end{gathered}
$$

Perturbations in the steady-state values of state variables and the duty cycle are as follows:

$$
\left\{\begin{array}{l}
x=X+\hat{x} \\
d_{1}=\mathrm{D}_{1}+\hat{d}_{1} \\
d_{2}=\mathrm{D}_{2}+\hat{d}_{2} \\
u=U+\hat{u} \\
y=Y+\hat{y}
\end{array}\right.
$$

where $\hat{x}_{x} \hat{d}_{1}, \hat{d}_{2}, \hat{w}, \hat{y}$ are the state variable $x$, the duty cycle $d_{1}$, the duty cycle $d_{2}$, the input voltage $u$, and the disturbance component near the $y$ static operating point. Substituting (31) into (8), the relationship between $\hat{d}_{1}$ and $\hat{d}_{2}$ can be obtained as follow:

$$
\hat{d}_{2}=\frac{U_{\text {in }} \hat{d}_{1}-\mathrm{D}_{2} \hat{U}_{C 1}}{U_{C 1}-U_{\text {in }}} .
$$

TABLE II

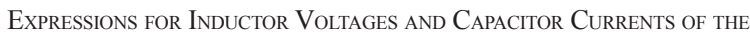
Inverter in the Positive Half Cycle

\begin{tabular}{lccc}
\hline & Mode I & Mode II & Mode III \\
& $\mathrm{D}_{1} T_{\mathrm{S}}$ & $\mathrm{D}_{2} T_{\mathrm{S}}\left(i_{L 1}>0\right)$ & $\mathrm{D}_{3} T_{\mathrm{S}}\left(i_{L 1}=0\right)$ \\
\hline$U_{L 1}$ & $U_{\text {in }}$ & $U_{\text {in }}-U_{C 1}$ & 0 \\
$U_{L 2}$ & $U_{C 1}-U_{C 2}$ & $-U_{C 2}$ & $-U_{C 2}$ \\
$i_{C 1}$ & $-i_{L 2}$ & $i_{L 1}$ & 0 \\
$i_{C 2}$ & $i_{L 2}-U_{C 2} / R_{\mathrm{O}}$ & $i_{L 2}-U_{C 2} / R_{\mathrm{O}}$ & $i_{L 2}-U_{C 2} / R_{\mathrm{O}}$ \\
\hline \hline
\end{tabular}

Substituting (31), (32) into (27) and writing $\hat{d}_{2}$ in terms of $\hat{d}_{1}$ and neglecting higher order terms, small-signal AC model represented in matrix form is obtained as:

$$
\left\{\begin{array}{l}
\hat{\hat{x}}=A \hat{x}+B \hat{u}+E \hat{d} \\
\hat{y}=C \hat{x}
\end{array}\right.
$$

where the coefficient matrixes $A, B, E$ and $C$ can be calculated by the following formulas:

$$
\begin{gathered}
A=\left[\begin{array}{cccc}
0 & 0 & 0 & 0 \\
0 & 0 & \frac{\mathrm{D}_{1}}{L_{2}} & -\frac{1}{L_{2}} \\
\frac{\mathrm{D}_{2}}{C_{1}} & -\frac{\mathrm{D}_{1}}{C_{1}} & \frac{\mathrm{D}_{2} i_{L 1}}{C_{1}\left(U_{\mathrm{in}}-U_{C 1}\right)} & 0 \\
0 & \frac{1}{C_{2}} & 0 & -\frac{1}{R C_{2}}
\end{array}\right] \\
E=\left[\begin{array}{cccc}
0 & \frac{U_{C 1}}{L_{1}} & -\frac{i_{L 2}}{C_{1}}+\frac{U_{\text {in }} i_{L 1}}{C_{1}\left(U_{C 1}-U_{\text {in }}\right)} & 0
\end{array}\right] \\
C=\left[\begin{array}{llll}
0 & 0 & 0 & 1
\end{array}\right]
\end{gathered}
$$

Based on the small signal model given by (33) and the control $(d)$ to output voltage $\left(U_{\mathrm{O}}\right)$ transfer function $G_{\mathrm{p}}(s)$ is obtained as follow:

$$
G_{\mathrm{P}}(s)=\left.\frac{y(s)}{d(s)}\right|_{U(s)=0}=\left.\frac{U_{0}(s)}{d(s)}\right|_{U(s)=0}=C(S I-A)^{-1} E
$$

Using the parameters given in Table III, the transfer function $G_{\mathrm{p}}(s)$ can be obtained as (39).

$G_{\mathrm{P}}(s)=\frac{\hat{U}_{\mathrm{O}}(s)}{\hat{d}(s)}=\frac{4.68 \times 10^{9} S+1.673 \times 10^{12}}{S^{3}+7 \times 10^{3} S^{2}+5.88 \times 10^{7} S+2.36 \times 10^{10}}$

\section{B. Controller Design}

In addition, it is necessary to design a suitable controller 
TABLE III

PARAMETERS OF INVERTER Circuit

\begin{tabular}{lc}
\hline \hline Experimental variable & Value \\
\hline DC input voltage $U_{\text {in }}$ & $45 \sim 70 \mathrm{~V}$ \\
AC output voltage $u_{\mathrm{O}}$ & $110 / 50 \mathrm{~V}(\mathrm{~Hz})$ \\
Switching frequency $f_{\mathrm{S}}$ & $20 \mathrm{kHz}$ \\
Rated power $P_{\mathrm{O}}$ & $200 \mathrm{~W}$ \\
DC boost inductor $L_{1}$ & $110 \mu \mathrm{H}$ \\
DC bus capacitor $C_{1}$ & $47 \mu \mathrm{F}$ \\
Switch $\mathrm{S}_{1} \sim \mathrm{S}_{5}$ & BSM $100 \mathrm{~GB} 60 \mathrm{DLC}$ \\
Diode $\mathrm{D}_{1}$ & RHRG3060 \\
Filter inductance $L_{2}$ & $3 \mathrm{mH}$ \\
Filter capacitor $C_{2}$ & $10 \mu \mathrm{F}$ \\
\hline \hline
\end{tabular}

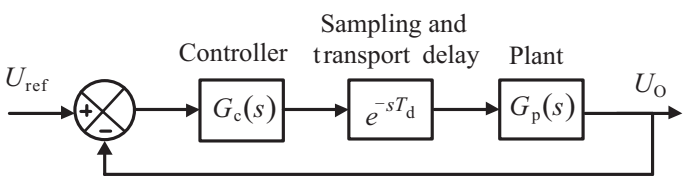

Fig. 8. Voltage control block diagram.

to achieve a good steady-state performance and dynamic characteristics. PR controller is advantageous in tracking sinusoidal signals as it provides a high gain at grid frequency, thereby eliminating the steady state error [23]. Fig. 8 shows the block diagram representation of the voltage control loop including the PR controller $G_{\mathrm{c}}(s)$. As shown in Fig. 8, these delays are added and incorporated into the control loop as $e^{-s T_{d}}$, where $T_{\mathrm{d}}=0.75 T_{\mathrm{s}}$. To minimize the steady state error at grid frequency, PR controller is tuned to grid frequency of $50 \mathrm{~Hz}$. This ensures high loop gain at the grid frequency. The transfer function is as follow:

$$
T_{\mathrm{c}}(s)=\frac{S^{2}+\zeta_{\mathrm{z}} \omega S+\omega^{2}}{S^{2}+\zeta_{\mathrm{p}} \omega S+\omega^{2}},
$$

where $\omega$ is the required frequency, $\zeta_{\mathrm{z}}$ and $\zeta_{\mathrm{p}}$ are the damping coefficients [24].

The controller gain depends on the ratio of the damping coefficients. For a steady state error of $0.1 \%$, values of $\zeta_{z}$ and $\zeta_{p}$ are obtained as 1 and 0.5 respectively.

The Bode plot of $G_{\mathrm{p}}(s)$ and the open loop gain $G(s)=G_{\mathrm{c}}(s)$ $\times e^{-s T_{\mathrm{d}}} \times G_{\mathrm{p}}(s)$ are shown in Fig. 9. It can be seen that the gain is high at resonant frequency, which is the grid frequency and hence, the steady state error is negligible at grid frequency.

\section{SimUlation and Experimental Verifications}

In order to verify the correctness of the feasibility and theoretical analysis of the proposed boost inverter in this paper, the simulation is carried out firstly. Then, an experimental prototype taking DSP320F2812 as core controller is built to verify the performance of inverter. The specific parameters are shown in Table III. Fig. 10 shows the external view of the prototype.

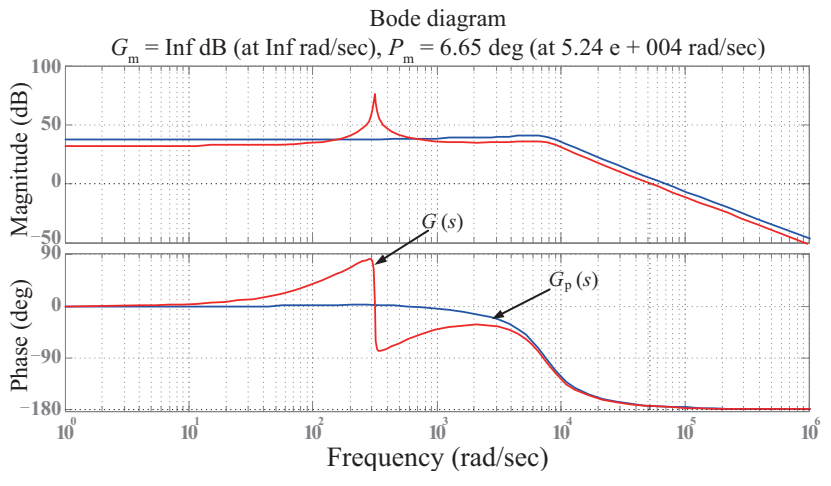

Fig. 9. Bode plots of the transfer functions $G_{\mathrm{p}}(s)$ and $G(s)$.

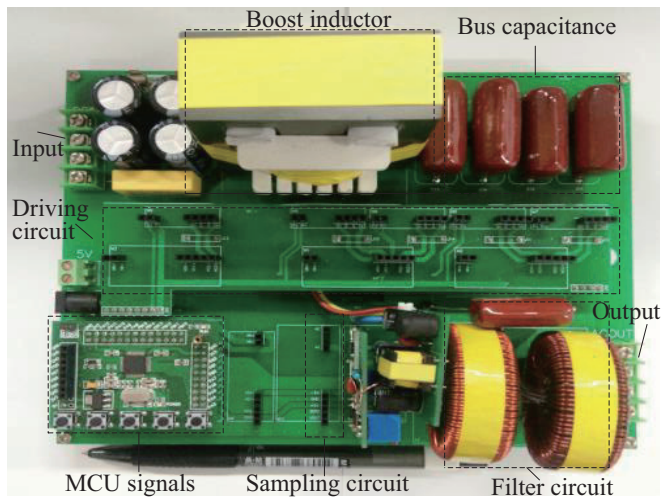

Fig. 10. The external view of the proposed inverter.

The modulation ratio $m$ is 0.7 and the input voltage $U_{\text {in }}$ is $45 \mathrm{~V}$. The waveforms of the inverter are shown in Fig. 11. Fig. 11(a) shows the driving signals of all switches. Fig. 11(b) shows the output voltage of inverter and the current of input inductor $L_{1}$. Fig. 11(c) shows the DC bus voltage $u_{C 1}$ and the output voltage across the load. The current through the filter $L_{2}$ and output current are shown in Fig. 11(d). Fig. 12 is experimental waveform of the voltage stress for power devices. The measured efficiency under different input voltage are shown in Fig. 13. The performance comparison with the single stage topologies in [25]-[26] is presented in Table IV.

\section{Conclusions}

A transformerless boost inverter topology for stand-alone photovoltaic generation systems is proposed in this paper, which can work in a wide input voltage range. The integrated boost inverter can be derived from a boost converter and a full bridge inverter by multiplexing the switch of basic boost converter. In the proposed inverter, only one power device is operated at high frequency in a line frequency cycle, the other one is operated at high frequency in half cycle, and the rest switches are all operated in low frequency of $50 \mathrm{~Hz}$. In addition, values of the boost inductor $L_{1}$ and the bus capacitor $C_{1}$ can be designed to be very small so that the volume and the cost of the circuit are significantly reduced. The operating principle and steady-state characteristics of the inverter are analyzed in detail when the input inductor current is designed in DCM. The correction of the theoretical analysis is proved by 


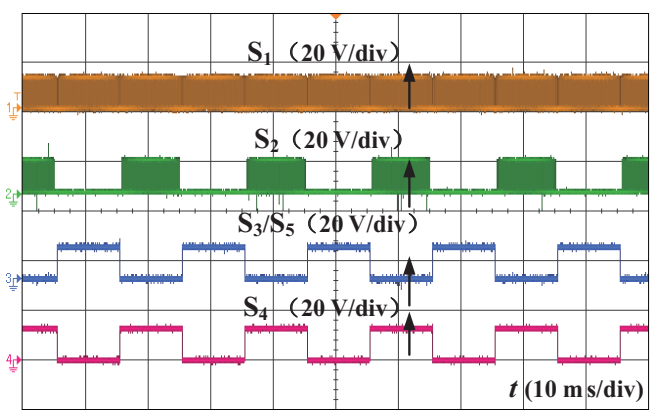

(a)

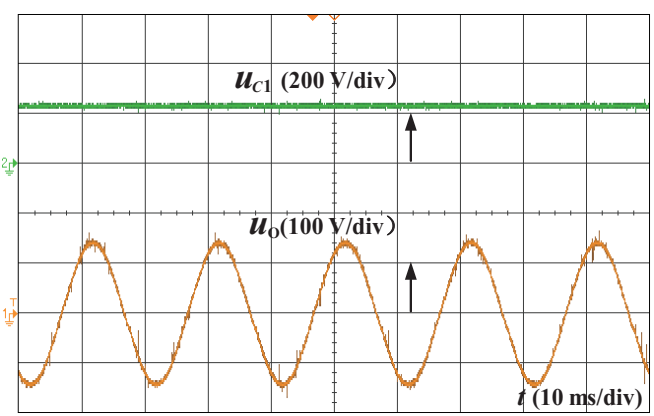

(c)

Fig. 11. Experimental waveforms. (a) $u_{\mathrm{g}, \mathrm{S} 1} \sim u_{\mathrm{g}, \mathrm{S} 5}$. (b) $u_{\mathrm{ab}}, i_{L 1} / i_{\mathrm{in}}$. (c) $u_{C 1}, u_{\mathrm{O}}$. (d) $i_{\mathrm{O}}, i_{L 2}$.
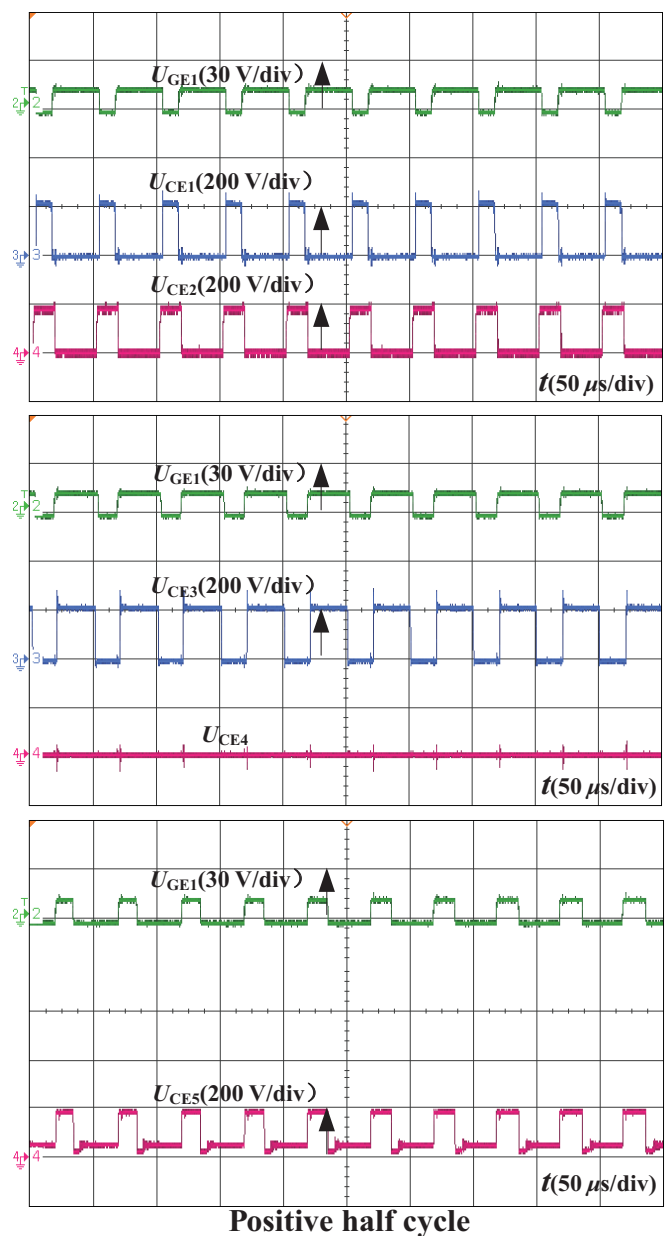

\section{Positive half cycle}

Fig. 12. Experimental waveforms of the power switches.

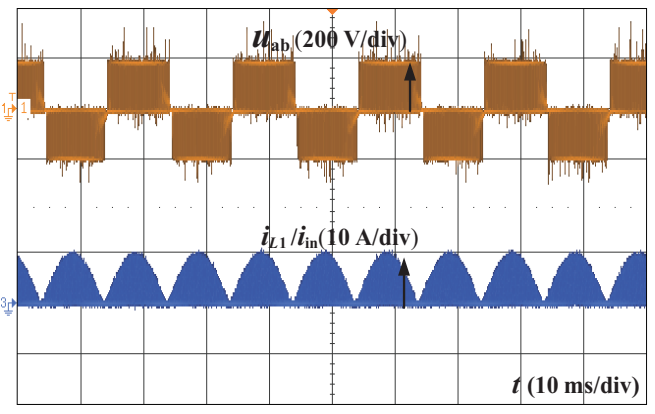

(b)

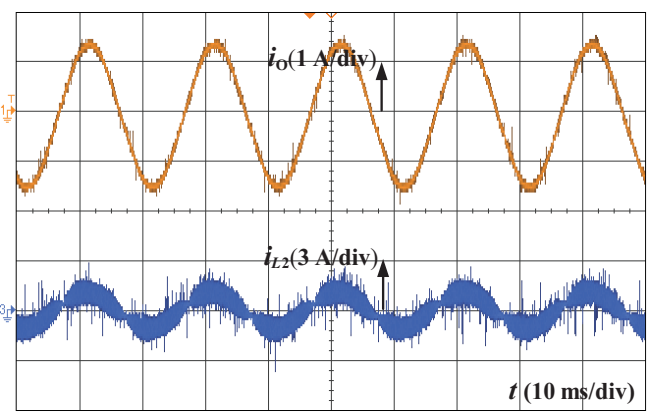

(d)
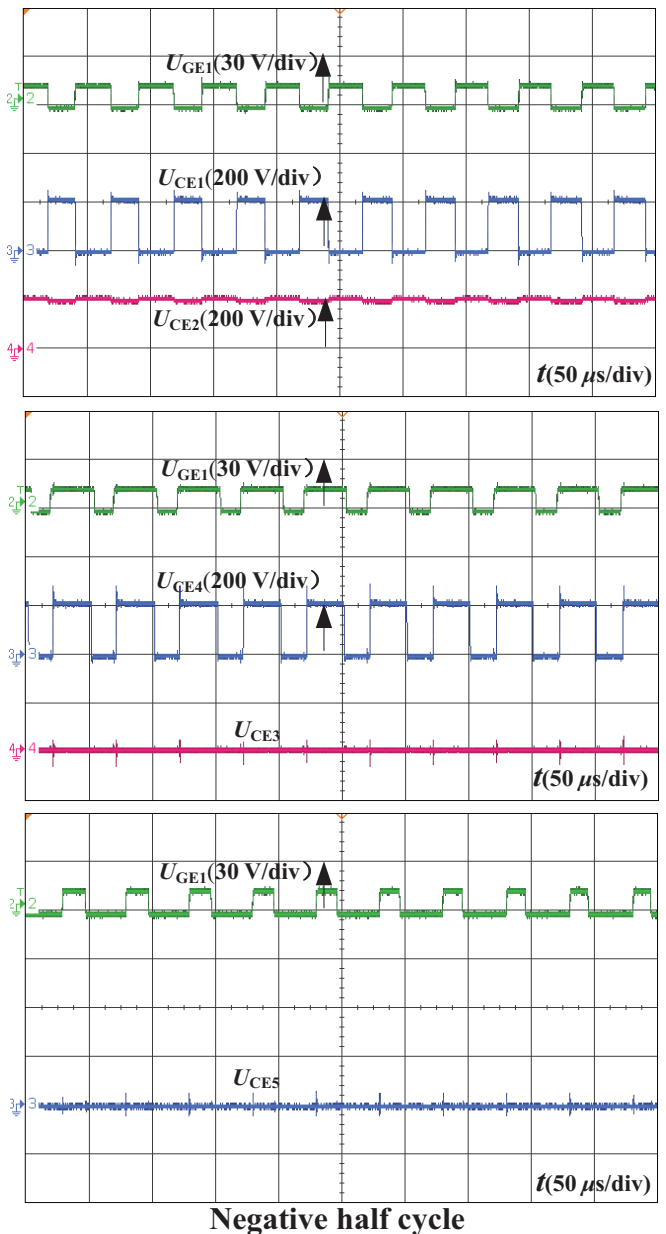

Negative half cycle 


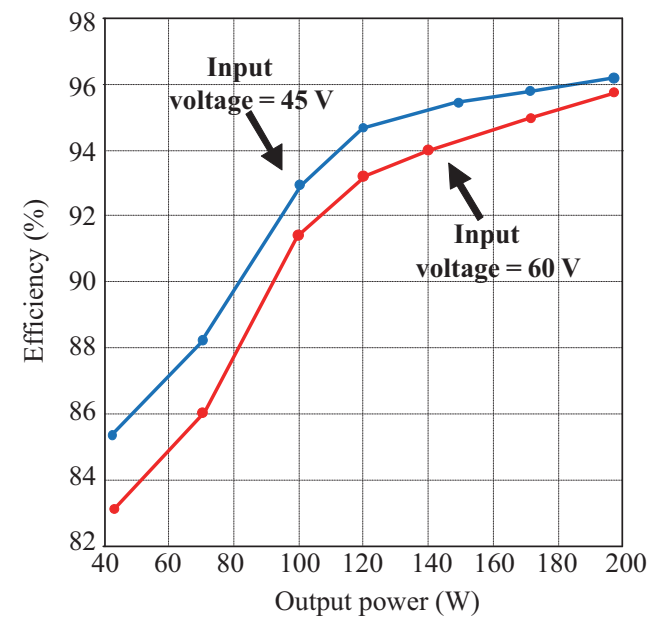

Fig. 13. The efficiency curves for different conditions.

TABLE IV

Comparison of Single-Stage Inverter Topologies

\begin{tabular}{|c|c|c|c|c|c|c|}
\hline \multirow[t]{2}{*}{ Topology } & \multicolumn{4}{|c|}{$\begin{array}{c}\text { Components \& } \\
\text { Devices }\end{array}$} & \multirow[t]{2}{*}{ THD (\%) } & \multirow[t]{2}{*}{ Max.eff $(\%)$} \\
\hline & $\mathrm{S}$ & $\mathrm{D}$ & $\mathrm{L}$ & $\bar{C}$ & & \\
\hline [25] & 4 & 3 & 3 & 2 & 4 & 91.3 \\
\hline [26] & 6 & 0 & 2 & 2 & - & 92.6 \\
\hline Proposed & 5 & 1 & 2 & 2 & 1.8 & 96.2 \\
\hline
\end{tabular}

the experimental waveforms.

\section{REFERENCES}

[1] Q. Yang, W. X. Huang, Y. W. Hu, et al., "A new type single stage boost inverter," in Transactions of China Electrotechnical Society, vol. 26, no.4, pp.122-127, 2011.

[2] L. Q. Wang, B. N. Zhu, and X. F. Sun, "A single stage isolated type Sepic inverter," in Transactions of China Electrotechnical Society, vol. 31, no. 18, pp. 75-82, 2016.

[3] L. Zhang, X. B. Ruan, and X. Y. Ren, "The control method of the front stage DC converter in the two stage inverter," in Proceedings of the CSEE, vol. 35, no. 3, pp. 660-670, 2015.

[4] F. Z. Peng, "Z-source inverter," in IEEE Transcations on Industry Applications, vol. 39, no. 2, pp. 504-510, 2003.

[5] X. Q. Guo and R. He, "Leakage current reduction of Z-source four-leg inverter for transformerless PV system," Applied Power Electronics Conference and Exposition (APEC), pp: 380-383, 26-30 March 2017.

[6] E. S. Asl, E. Babaei, M. Sabahi, et al, "New half-bridge and full-bridge topologies for switched-boost inverter with continuous input current," in IEEE Transcations on Industrial Electronics, vol. 65, no. 4, pp. 31883197, 2018.

[7] F. A. A. Meinagh, E. Babaei, and H. Tarzamni, "Modified high voltage gain switched boost inverter," in IET Journals \& Magazines, vol. 10, no. 13, pp.1655-1664, 2017.

[8] R. Hugo, B. Beatriz, and P. Andre, "Single-stage DC-AC converter for photovoltaic system," in Proceedings ECCE, pp. 604-610, Sept., 2010.

[9] K. Jha, S. Mishra, and A. Joshi, "High-quality sine wave generation using a differential boost inverter at higher operating frequency," in IEEE Transcations on Industry Applications, vol. 51, no. 1, pp.373-384, 2015.

[10] L. Q. Wang and X. Wang, "A novel single-stage non-isolated dual Cuk inverter," Proceedings of the CSEE, vol. 34, no. 6, pp. 846-854, 2014.

[11] P. K. Chamarthi, M. Rajeev, and V. Agarwal, "A novel single stage zero leakage current transformer-less inverter for grid connected PV systems," in Proceedings PVSC, pp. 1-5, June, 2015.

[12] L. Qin, M. Hu, D. C Lu, Z. Feng, and Y. Wang, "Buck-boost dual-legintegrated step-up inverter with low THD and single variable control for single-phase high-frequency AC microgrids," in IEEE Transcations on Power Electronics, vol. 33, no. 7, pp. 6278-6291, 2018.

[13] A. Alexander and S. Keyue, "High-gain single-stage boosting inverter for photovoltaic applications," in IEEE Transcations on Power Electronics, vol. 31, no. 5, pp. 3550-3558, 2016.

[14] B. Zhao, A. Abramovitz, R. Ma, and Y. Huangfu, "High gain single stage buck-boost inverter," in Proceedings ICEMS, pp. 1-5, 2017.

[15] T. Sreekanth, N. L. Narasamma, M. K. Mishra, "A high gain grid connected single stage inverter system with reactive power control,"in Proceedings ICIT, pp.358-363, 2017.

[16] V. K. Bussa, A. Ahmad, R. K. Singh, and R. Mahanty, "Single-phase high-voltage gain switched LC Z-source inverters," in IET Journals \& Magazines, vol. 11, no. 5, pp.796-807, 2018.

[17] X. Guo, "A novel CH5 inverter for single-phase transformerless photovoltaic system applications," in IEEE Transactions on Circuits and Systems II: Express Briefs, vol. 64, no. 10, pp. 1197-1201, Oct. 2017.

[18] T. Sreekanth, N. Lakshminarasamma, and M. K. Mishra, "Coupled inductor-based single-stage high gain DC-AC buck-boost inverter," in IET Power Electronics, vol. 9, no. 8, pp.1590-1599, 2016.

[19] X. F. Hu, P. H. Ma, B. B. Gao, et al, "An integrated step up inverter without transformer and leakage current for grid-connected photovoltaic system," in IEEE Transactions on Power Electronics, vol. 34, no. 10, pp. 9814-9827, Oct. 2019.

[20] Z. Yu, X. Hu, M. Zhang, L. Chen, and S. Jiang, "A transformerless boost inverter for stand-alone photovoltaic generation systems," 2019 IEEE 10th International Symposium on Power Electronics for Distributed Generation Systems (PEDG), Xi'an, China, 2019, pp. 570-575.

[21] C. Sun, J. Lin, and Z. N. Zhu, "Research on SPWM combined boost DC/ AC converter," in Electrotechnical Application, No. 6, pp.10-12, 2001.

[22] L. G. Zhang and Z. Z. Liu, "Research and design of LC filter for SPWM inverter power supply," in Design of Electronic Engineering, vol. 22, no. 6, pp.172-174, 2014.

[23] D. Zmood and D. G. Holmes, "Stationary frame current regulation of PWM inverters with zero steady-state error," in IEEE Transcations Power Electronics, vol. 18, no. 3, pp. 814-822, May 2003.

[24] V. Gautam, Ashok kumar, and P. Sensharma, "A novel single stage transformer less PV inverter," 2014 IEEE International Conference on Industrial Technology, pp. 907-912, Feb. 2014.

[25] A. Abramovitz, B. Zhao, and K. M. Smedley, "High-gain single-stage boosting inverter for photovoltaic applications," in IEEE Transcations on Power Electronics, vol. 31, no. 5, pp. 3550-3558, May 2016.

[26] Y. Tang, Y. Bai, J. Kan, and F. Xu, "Improved dual boost inverter with half cycle modulation," in IEEE Transcations on Power Electronics, vol. 32, no. 10, pp. 7543-7552, Oct. 2017.

[27] X. Guo, N. Wang, J. Zhang, B. Wang, and M. Nguyen, "A novel transformerless current source inverter for leakage current reduction," in IEEE Access, vol. 7, pp. 50681-50690, 2019.

[28] H. Wang, W. Wu, S. Zhang, Y. He, H. S. Chung, and F. Blaabjerg, "A modified Aalborg inverter extracting maximum power from one $\mathrm{PV}$ array source," in CPSS Transactions on Power Electronics and Applications, vol. 4, no. 2, pp. 109-118, June 2019.

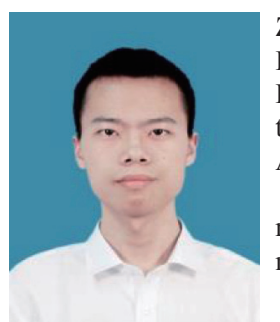

Zhixiang Yu received the B.S. degree in Electrical Engineering from Huaiyin Institute of Technology, Huaian, China, in 2018. Currently he is working toward the M.S. degree in Electrical Engineering in Anhui University of Technology, Ma'anshan, China. His research interests include power converters, renewable energy generation systems and the modeling of converters. 


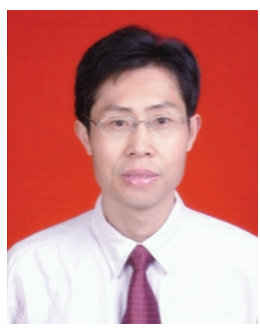

Xuefeng Hu received his M.S. degree in Electronic Engineering from the China University of Mining and Technology, Xuzhou, China, in 2001; and the Ph.D. degree in Electrical Engineering from the Nanjing University of Aeronautics and Astronautics (NUAA), Nanjing, China, in 2004.

$\mathrm{He}$ is presently working as a Professor in Anhui University of Technology, Ma'anshan, China. He is the author or coauthor of more than 40 technical papers. His current research interests include renewable energy systems, the modeling and control of converters, flexible ac transmission systems and distributed power systems.

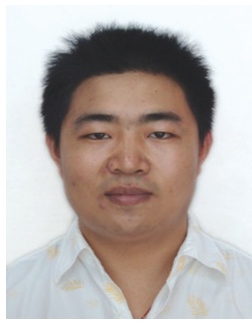

Zhilei Yao was born in Jiangsu Province, China, in 1981. He received the M.S., and Ph.D. degrees in electrical engineering from Nanjing University of Aeronautics and Astronautics, Nanjing, China, in 2006 , and 2012, respectively.

He was a visiting scholar at Department of Energy Technology, Aalborg University from Nov. 2014 to Nov. 2015. He is currently a Professor at the Yancheng Institute of Technology, Yancheng, China. He holds more than 50 patents, and is the author or coauthor of more than 90 technical papers. His current research interests include dc-dc converters, inverters, and distributed power generation.

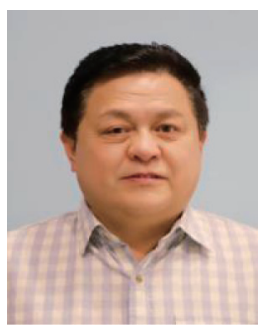

Lezhu Chen received the M.S. degree from University of Science and Technology Beijing, Beijing, China, in 1989. He is currently a Professor at the College of Electrical Engineering, Anhui University of Technology, Ma'anshan, China. His current research interests include smart grid control, power quality detection and control, and application electronics.

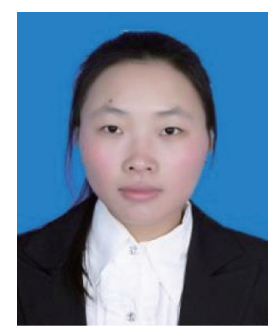

Meng Zhang received the B.S. degree from the Jilin Jianzhu University, Changchun, China, in 2016. She received the M.S. degree from the College of Electrical Engineering, Anhui University of Technology, Ma'anshan, China, in 2019.

Her current research interests include power electronics and solar and wind power generation.

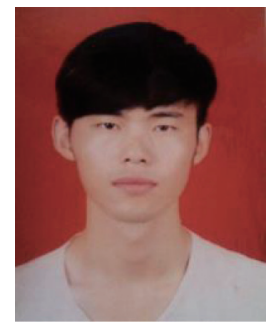

Shunde Jiang was born in Anhui Province, China, in 1995. He received his B.S. degree from the Linyi University, Linyi, China, in 2018.He is presently working towards his M.S. degree in the College of Electrical Engineering, Anhui University of Technology, Ma'anshan, China.

His current research interests include power electronics, dc-ac power conversion, and solar and wind power generation. 